\title{
Assessing the Impact of Sulfur Atmospheric Deposition on Terrestrial Ecosystems Close to an Industrial Corridor in the Southeast of Mexico
}

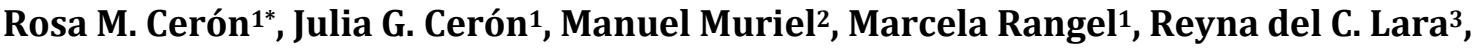 \\ Beatriz Tejero ${ }^{4}$, Martha P. Uc ${ }^{1}$, Abril Rodríguez ${ }^{1}$ \\ ${ }^{1}$ Chemistry Faculty, Autonomous University of Carmen, Ciudad del Carmen, Campeche, Mexico \\ ${ }^{2}$ Mexican Institute of Petroleum, Marine Zone, Ciudad del Carmen, Campeche, Mexico \\ ${ }^{3}$ Sciences of Health Faculty, Autonomous University of Carmen, Ciudad del Carmen, Campeche, Mexico \\ ${ }^{4}$ Center of Environmental Sciences Research, Autonomous University of Carmen, Ciudad del Carmen, Campeche, Mexico \\ Email: ^rceron@pampano.unacar.mx
}

How to cite this paper: Cerón, R.M., Cerón, J.G., Muriel, M., Rangel, M., Lara, R.C., Tejero, B., Uc, M.P. and Rodríguez, A. (2017) Assessing the Impact of Sulfur Atmospheric Deposition on Terrestrial Ecosystems Close to an Industrial Corridor in the Southeast of Mexico. Journal of Environmental Protection, 8, 1158-1177. https://doi.org/10.4236/jep.2017.810073

Received: August 21, 2017

Accepted: September 23, 2017

Published: September 26, 2017

Copyright () 2017 by authors and Scientific Research Publishing Inc. This work is licensed under the Creative Commons Attribution International License (CC BY 4.0).

http://creativecommons.org/licenses/by/4.0/ (c) (i) Open Access

\begin{abstract}
The main objective of this research work was to diagnose the vulnerability of terrestrial ecosystems to $S$ deposition in Atasta region in Campeche State, Mexico, comprising two simultaneous sampling programs in both, soil and atmospheric deposition on an annual basis during three climatic periods: dry, rainy and cold fronts seasons. From the estimation of soil properties estimation ( $\mathrm{pH}$, texture, mineralogy, cationic exchange capacity, and basis saturation \%), critical loads and sensitivity classes were assigned to sampled soils based according to the empirical methodology proposed by UNECE. During the dry season, 10 sites fell into sensitivity class 2 (moderately sensitive) and 3 (sensitive). On the other hand, during the rainy season, 8 sites showed a sensitivity class 1 (highly sensitive) and 2 sites presented a sensitivity class 2 (moderately sensitive); whereas along cold fronts season, 12 sites fell into sensitivity class 1 that corresponds to highly sensitive. Sensitivity classes showed a seasonal trend, with a higher sensitivity during rainy and cold fronts seasons; this agrees with the kind of sources influencing on the study area as a result of the prevailing meteorology during these climatic periods. Likewise, S concentration in atmospheric deposition was determined by turbidimetric method, and $S$ deposition fluxes were estimated from surface area of the funnel opening of the sampling device and the sampling period. $S$ deposition fluxes ranged from 0.29 and $14.06 \mathrm{~kg} \mathrm{~S} \mathrm{ha}^{-1} \cdot \mathrm{yr}^{-1}$; with a mean value of $8.57 \mathrm{~kg} \mathrm{~S} \mathrm{ha}^{-1} \cdot \mathrm{yr}^{-1}$. From
\end{abstract}


the comparison between the current deposition rates and proposed critical loads, exceedances percentages were obtained (from $1.65 \%$ to $62.8 \%$ ) and mapped to identify critical zones of $\mathrm{S}$ deposition in the studied area. It was established the important role which mangrove vegetation plays in the attenuation of the potential ecological effects on terrestrial ecosystems of the study area associated to atmospheric deposition.

\section{Keywords}

Atmospheric Deposition, Critical Loads, Sulfur, Campeche, Mexico

\section{Introduction}

The qualitative and quantitative assessing of atmospheric deposition is essential to establish a baseline or estimate the background levels present in a given site, to propose critical load values, to assess the vulnerability of ecosystems, to identify sensitive zones with a potential to exceed critical loads, to assess seasonal and inter-annual trends, and to identify spatial and temporal distribution patterns [1]. Based on this, it is possible to propose protection and conservation measures, and finally, in a medium term, to demonstrate the efficacy of environmental policies applied in matter of emissions reduction [2] [3].

$\mathrm{N}$ and $\mathrm{S}$ deposition fluxes have reached levels that cause alterations in the structure and function of several ecosystems. Therefore, the potential ecological effects derived from atmospheric deposition, constitute one of the main concerns of society [4]. The detailed study of this phenomenon, as well as the assessment of its spatial and temporal distribution in a given region, allows decision-makers develop public policies focused to preserve and protect natural resources that could be vulnerable to suffer damages as a result of atmospheric deposition. In this regard, it is necessary to take in account, that ecosystems differ in their sensitivity to acid deposition depending on the buffer capacity of the soils, of soil composition, and of the sensitivity of organisms that inhabit them to the changes in solution or chemical reactions occurring in them [5].

An approach that allows to quantify the amount of pollutants deposition that can damage ecosystems is the estimation of critical loads. Critical loads constitute quantitative estimations about sensitivity of the ecosystems. These values were developed as a tool in 80 's and 90's decades through Nordic Cooperation, being obtained in Europe and United States of America to investigate the potential impact of acid deposition in different ecosystems. A critical load can be defined as the quantitative estimation of exposure to one or more pollutants, below which, significant detrimental effects for the environment do not occur [6].

In general, critical loads can be estimated at three levels of complexity: level 0 , level 1, and level 2. At "level 0", critical loads are empirically assigned to soils with different sensitivity using existing data. A critical load categorized as "level 
1" corresponds to a method using a mass balance calculation as steady state models (SMB model); whereas, a critical load with a "level 2" is derived from methods that use dynamic models that requires detailed information [7].

In the case of Mexico, methods "level 1" and "level 2" to derive critical loads are not useful since, empirical loads are not available at a national scale, and due to the limited information of data; therefore, a "level 0" approach must be applied as a first approximation to estimate critical loads.

Besides this, to establish critical load values, and to estimate their exceedances in a given site, atmospheric deposition measurements are required [2] [8] [9]. However, to determine the current inputs of nitrogen and sulfur to the ecosystems, the most of deposition maps are based on results of tridimensional chemical transport models that require to be validated by comparison with field measurements. This kind of study constitutes a valuable opportunity for decision-makers to identify potential impacts associated with different emission sources and, to assess their geographical and temporal distribution. The mapping of sensitivity and the critical load approach, constitute methods that allow to analyze these risks.

Additionally, several methods have been developed to calculate and to map critical loads not only at a regional scale, even at national and global scale [6]. The global assessments reported in other research works include maps and data, that give a preliminary diagnosis of the sensitive areas to acid deposition in regions of Europe, Canada, United Sates, China, Japan and Australia [1] [9] [10] [11]. However, unfortunately, in relation to another places in the world, as the case of developing countries, there is not enough information [2] [3] [12]. Particularly, in Mexico, excepting some threshold values reported for pine forests [9] [13] [14], there are not any data or maps available that show N and S deposition fluxes distribution for vulnerable zones. Since, reference values are not available for Mexican ecosystems, the few studies that have been done in this regard, usually compare the $\mathrm{N}$ and $\mathrm{S}$ current deposition fluxes with critical load values reported for Europe and United States. It is relevant to investigate in which extent, the empirical critical load approach can be applied in developing countries with ecosystems and climate very different, and where required data are scarce or are not available [2].

However, it is necessary to consider that deposition patterns, the biodiversity and the response of sensitive organisms in tropical countries as Mexico, can be different to those existing in temperate regions in mid-latitudes. Considering the difficulties in the application of this methodology in areas outside Europe, this work applied an empirical method to diagnose the sensitivity of terrestrial ecosystems to $S$ atmospheric deposition in the Atasta region, by estimating a critical load "level 0", by comparing with the estimated current deposition fluxes to calculate their exceedances. Finally, the findings were mapped to identify critical zones, and the role of mangrove vegetation in attenuation process of these effects was discussed. 


\section{Materials and Methods}

\subsection{Study Area}

This study was carried out in the region of Atasta in Campeche State, Mexico (Figure 1). Atasta is located in the western part of Terminos Lagoon, that comprises three communities (Xicalango, Puerto Rico and Atasta) and two important ecological regions (Terminos Lagoon and the Lagoon system named Pom-Atasta).

Atasta region is a coastal plain that runs parallel to the coastal line, located in Atasta peninsula, with an approximate surface of $190 \mathrm{~km}^{2}$, a length of $50 \mathrm{~km}$, and average depth of $2.7 \mathrm{~m}$. The main characteristics in this system are highly dependent on geomorphology, the tide influence, the exchange of water mass with Terminos Lagoon, and the influence of climatic phenomena. Dominant vegetation is mangrove.

Climate in this region is sub-humid warm with rains occurring along summer and autumn seasons. The annual average rainfall is $1300 \mathrm{~mm}$ and the annual average temperature is $27^{\circ} \mathrm{C}$. Prevailing winds come from NE from March to October, when this region is under the influence of cold fronts named "Nortes", and from SE during the rest of the year, when the region is influenced by tropical maritime air as a result of trade winds. In addition, this region is influenced by earth and sea breezes as a result of differential heating between land and sea. This area constitutes a hotspot in Mexico due to the following reasons: 1) its proximity to offshore platforms area in Campeche Sound; and 2) its proximity to Natural protected named “Terminos Lagoon”.

\subsection{Sampling}

A multiple transects design with 13 sampling points (P1-P13) was utilized. Sampling points location is presented in Figure 1. Sampling period included three

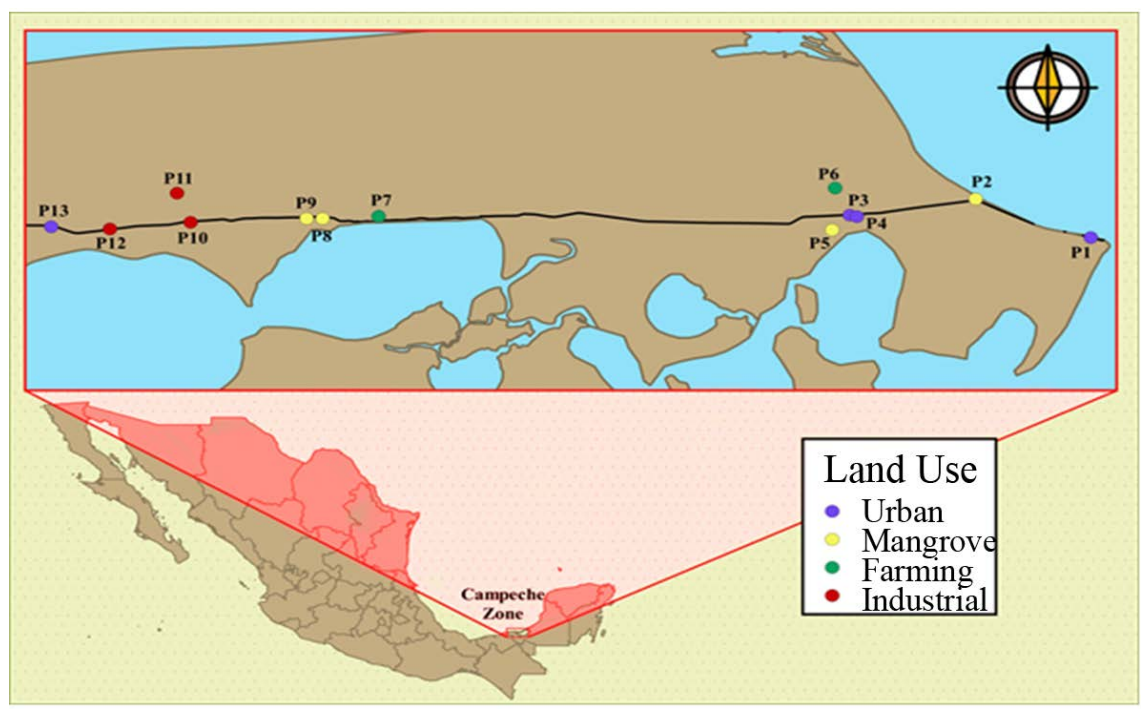

Figure 1. Sampling points location. 
seasons in an annual basis during 2015 and 2016: Dry (From March to June, 2015); Rainy (From July to October, 2015) and Cold Fronts (From November 2015 to February 2016).

\subsubsection{Soil Sampling}

A Transects were constituted by two quadrants separated one meter away. Each quadrant was composed by 4 points with $0.40 \mathrm{~m}$ of separation. Sampling was carried out by using a core sampler with a volume of $193.3 \mathrm{~cm}^{3}$ at $0.30 \mathrm{~m}$ depth, obtaining a composite sample for each sampling point for three climatic period. Composite samples were dried at ambient temperature $\left(25^{\circ} \mathrm{C}\right)$ during 15 days, grounded and sieved $(500 \mu \mathrm{m})$. Finally, dried samples were stored in sealed and tagged plastic bags until their analysis.

\subsubsection{S Deposition Fluxes Sampling}

Automatic deposition collectors are expensive and require to fulfill with specific requirements for their installation and operation, whereas passive samplers as through fall devices due to their low cost allow to increase the density of the sampling grid to assess spatial and temporal patterns in a given site. For this reason, in this research work, sampling devices used to collect $S$ atmospheric deposition fluxes were those reported by [5] [15]. These sampling devices are based in exchange resin columns with a mixed bed (Amberlite IRN 150) to collect specific ions that are retained along the resin column. This resin column is attached to a funnel (as collection surface), and has glass fiber at the top (as a filter to avoid the fall of leaves or insects) and at the bottom (as a resin support). Once, the hydrologic flux is collected by the funnel, it is channeled through the resin column, where ions are retained. At the end of each sampling period (climatic season), ions retained ( $\mathrm{S}$ as sulfate) were extracted by using extraction solutions to recover them $(2 \mathrm{~N} \mathrm{KCl}$ solution) and analyzed by turbidimetric method.

\subsection{Chemical Analysis}

\subsubsection{Soil Samples}

$\mathrm{pH}$ in soil samples was determined by potentiometric method [16]. Cationic Exchange capacity (CIC) and Interchangeable bases $\left(\mathrm{Ca}^{2+}, \mathrm{Mg}^{2+}, \mathrm{Na}^{2+} \mathrm{y} \mathrm{K}^{+}\right)$in calcareous soils was quantified by using silver thiourea as saturating solution [16]. Saturation Percentage of bases (\% SB) was determined according to NOM021-RECNAT-2000.

\subsubsection{S Atmospheric Deposition Fluxes}

$S$ deposition was estimated as sulfate, therefore, once extracted, atmospheric deposition samples obtained from passive sampling devices (collectors type through fall), were analyzed by turbidimetric method to obtain sulfate concentrations [17]. Extraction efficiency was calculated as the percentage of loaded ions on the column to the recovered in sequential extractions, obtaining an effi- 
ciency of approximately of $96.8 \%$. Finally, the surface area of the funnel opening and the sampling period were used to obtain $\mathrm{S}$ deposition fluxes for each sampling site as S Kg per land area per year $\left(\mathrm{kg} \mathrm{S} \mathrm{ha}^{-1} \cdot \mathrm{yr}^{-1}\right)$.

\subsection{Skokloster Method}

To assess the vulnerability of terrestrial ecosystems in Atasta region to $\mathrm{S}$ atmospheric deposition, the empirical method proposed by Kulylenstierna et al. [2] based on Skokloster methodology was applied. According to Skokloster workshop [18], the rate of chemical weathering of minerals is the main factor that determines critical loads for forest soils.

From this, soil materials are divided in five classes basing on dominant mineralogy. Consequently, critical load ranges are assigned to these classes, considering cationic exchange capacity (CIC) and saturation percentage of bases (\% SB). Kuyenstierna et al. [2] modified Skokloster method to use CIC and \% SB to assign sensitivity classes (Table 1), and as consequence, to assign critical load values for S (Table 2). This same methodology has been used by Duan et al. [19] to map critical loads of deposition level "0" for soils in China.

This method assesses the relative sensitivity by using representative variables of mineral weathering of soils, many of which are difficult to measure, calculate or map. Saturation percentage of bases reflects the weathering rate of soils, and it is a variable easy to measure, that constitutes the net result between the gain and the loss of basic ions from soils. As CIC and \% SB increases, sensitivity of ecosystems to $\mathrm{S}$ atmospheric deposition decreases.

\subsection{Data Interpolation and Mapping}

Point measurements obtained in this work were interpolated by using kriging

Table 1. Sensitivity classes as a function of CIC. (1: Highly sensitive; 2 : Moderately sensitive; 3: Sensitive; 4: Poorly Sensitive and 5: Not sensitive).

\begin{tabular}{cccccccc}
\hline & \multicolumn{6}{c}{$\%$ SB } \\
\cline { 3 - 7 } & & $0-20$ & $20-40$ & $40-60$ & $60-80$ & $80-100$ \\
\hline \multirow{3}{*}{ CIC (meq/100 g) } & $<10$ & 1 & 1 & 2 & 3 & 5 \\
& $10-25$ & 1 & 2 & 3 & 4 & 5 \\
& $>25$ & 2 & 3 & 4 & 5 & 5 \\
\hline
\end{tabular}

Table 2. Critical load relative to sensitivity class assigned.

\begin{tabular}{ccc}
\hline \multirow{2}{*}{$\begin{array}{c}\text { Sensitivity } \\
\text { classes }\end{array}$} & \multicolumn{2}{c}{ Critical load range $\left(\mathrm{meq} \cdot \mathrm{m}^{-\mathbf{2}} \cdot \mathrm{yr}^{-\mathbf{1}}\right)$} \\
\cline { 2 - 3 } 1 & Lower range & Upper range \\
2 & $0-25$ & $25-50$ \\
3 & $25-50$ & $50-100$ \\
4 & $50-100$ & $100-200$ \\
5 & $100-200$ & $200-400$ \\
& $>200$ (there is not a critical load) & $>400$ (there is not a critical load) \\
\hline
\end{tabular}


technique, therefore, to obtain $\mathrm{S}$ deposition fluxes maps, a geostatistical procedure was used to obtain field measurements into a continuous pattern (isolines) in the sampling grid of the study area (SURFER v.10.0). Once isolines were generated, data deposition was mapped for each climatic season to assess their spatial and temporal distribution. In addition, sensitivity classes were mapped for each climatic season to identify vulnerable zones.

\section{Results and Discussion}

\subsection{Sensitivity Class Assignment}

\subsubsection{Dry Season}

CIC levels in soils show the ability to retain cations, availability and amount of nutrients for plants. Soils with low values of CIC are poor in organic matter and indicate a low availability to retain nutrients. This capacity of soils allows to retain the necessary elements to give nutrients to plants, which otherwise would be in solution readily available for their leaching. Therefore, as CIC increases, the natural fertility increases. Soils are classified according to criteria established by Garrido [20] as a function of CIC and \% SB (Table 3, Table 4).

CIC values found during dry season ranged from 8.78 to $23.25 \mathrm{meq} / 100 \mathrm{~g}$, with the lowest value $(8.78 \mathrm{meq} / 100 \mathrm{~g})$ for site labeled as "P13" that corresponds to a soil classified as Gleysol, which is confirmed by permanently saturated soils in water (Table 5). On the other hand, the site that showed a greater value for CIC $(23.25 \mathrm{meq} / 100 \mathrm{~g})$ was the site labeled as "P10" that corresponds to a soil classified as Solonchak, characterized by presenting salts accumulation and not have a good drainage system (Table 5). However, in general, soils in the study area during the dry season showed a CIC from low to medium, so that, can be considered as soils from medium to poor with a requirement of organic matter, excepting by site "P13" that could be considered as very poor with a significant

Table 3. Soil classification as a function of CIC.

\begin{tabular}{ccc}
\hline CIC $\mathbf{~ m e q} / \mathbf{1 0 0} \mathbf{g}$ & Level & Characteristics \\
\hline $0-10$ & Very low & $\begin{array}{c}\text { Soils very poor, with an important deficiency } \\
\text { of organic matter }\end{array}$ \\
$10-20$ & Low & Soils poor, with a deficiency of organic matter \\
$20-35$ & Medium & Medium soils \\
$35-45$ & Medium high & Rich soils \\
$>45$ & High & Very rich soils \\
\hline
\end{tabular}

Table 4. Soil classification as a function of $\%$ SB.

\begin{tabular}{cc}
\hline$\%$ SB & Characteristics \\
\hline$<50$ & Soils very acid \\
$50-90$ & Medium soils \\
$>90$ & Soils saturated in bases, their exchange sites are being used
\end{tabular}


Table 5. Sensitivity classes assigned to sampling sites during dry season.

\begin{tabular}{ccccc}
\hline $\begin{array}{c}\text { Sampling } \\
\text { site }\end{array}$ & $\begin{array}{c}\mathrm{CIC} \\
(\mathrm{meq} / 100 \mathrm{~g})\end{array}$ & $\begin{array}{c}\left(\mathrm{Ca}^{2+}+\mathrm{Mg}^{2+}+\mathrm{Na}^{+}+\mathrm{K}^{+}\right) \\
\mathrm{meq} / 100 \mathrm{~g}\end{array}$ & $\begin{array}{c}\text { Sensitivity } \\
\text { class }\end{array}$ \\
\hline P1 & 19.48 & 1109.64 & 56.97 & 3 \\
P2 & 15.71 & 802.65 & 51.09 & 3 \\
P3 & 13.30 & 544.38 & 40.92 & 3 \\
P4 & 11.71 & 430.65 & 36.77 & 2 \\
P5 & 14.28 & 381.59 & 26.72 & 2 \\
P6 & 19.66 & 723.81 & 36.82 & 2 \\
P7 & 13.31 & 517.52 & 38.88 & 2 \\
P8 & 22.11 & 528.11 & 23.88 & 2 \\
P9 & 14.12 & 792.02 & 56.10 & 3 \\
P10 & 23.25 & 418.60 & 18.00 & 1 \\
P11 & 11.88 & 719.36 & 60.55 & 4 \\
P12 & 10.73 & 944.09 & 88.00 & 5 \\
P13 & 8.78 & 610.43 & 69.54 & 3 \\
\hline
\end{tabular}

deficiency in organic matter.

With respect to bases saturation (\% SB), their values were between $18 \%$ and $88 \%$. Site "P12" presented the highest value, whereas site "P10" has the lowest values (Table 5). Both sites correspond to soils classified as Solonchak; with salts accumulation, a bad drainage and a clay content below of $35 \%$. It could explain the reason why site "P10" presented the highest value of CIC, attributed to the salts accumulation process. Seven sampling points presented values below of $50 \%$, suggesting that, soils in the study area have important deficiencies in nutrients. The remaining six sites, presented values between $50 \%$ and $90 \%$, suggesting that they are medium soils whose wealth depend on total CIC values.

On the other hand, from Table 5, it can be observed that eight sampling sites reached sensitivity classes between 2 and 3 , that correspond to sensitivity categories of moderately sensitive and sensitive, respectively. Site "P10" obtained a sensitivity class of 1 (highly sensitive); whereas sampling sites labeled as "P11" and "P12", reached sensitivity classes of 4 and 5 (Poorly Sensitive and Not Sensitive, respectively). Site "P10" is an industrial site with a wet and sandy soil, the high content of humidity in this site results in a low \% SB (18\%), typical of soils classified as Solonchak, with a bad drainage, causing that exchangeable ions be leached from the soil, resulting in a low buffering capacity and a high sensitivity class (Class 1).

Otherwise, sites "P11" and "P12" are industrial sites with a low sensitivity although they are located near to a gas sour re-compression plant, since they have sandy and compact soils with a low content of humidity, result in \% SB values between $60.55 \%$ and $88 \%$, enhancing the buffering capacity and resulting in soils poorly sensitive to $\mathrm{S}$ atmospheric deposition during this seasonal period. 


\subsubsection{Rainy Season}

CIC values during the rainy season ranged from 0.06 to $22.07 \mathrm{meq} / 100 \mathrm{~g}$, with the lowest values in sites "P1" and "P10", respectively; that corresponds to soils type Arenosol and Solonchak. On the other hand, the site which presented the highest value for CIC was the site labeled a "P6" (22.07 meq/100 gr), with a soil classified as Arenosol, characterized by being depth and have a high salts concentration (Table 6).

In general, soils in the study area during rainy season presented CIC values very low. Ten sampling sites showed CIC values $<10 \mathrm{meq} / 100 \mathrm{~g}$, suggesting that they have soils very poor, and only three sampling sites presented CIC values between 10 and $20 \mathrm{meq} / 100 \mathrm{~g}$, pointing that they have poor soils with a deficiency of organic matter. Regarding \% SB, as saturation grade is higher, soils have a greater potential to retain cations. During the rainy season, \% SB ranged from $4.28 \%$ (site 4 ) to $99.29 \%$ (site P5).

It is necessary to consider that site "P5" is type Solonchak, with a high salts content, reflected by the highest CIC values found. On the other hand, site "P4" corresponds to a soil classified as Arenosol, characterized by being depth and have a high sand content. For this reason, during rainy season, the high grade of leaching resulted in \% SB values very low. Eight sampling sites of a total of thirteen, presented values below of 50\%; four sites showed $\%$ SB values between 50 and $90 \%$; and only one site had values greater than $90 \%$; suggesting that they have soils with deficiencies in nutrients and could be vulnerable or sensitive to $S$ atmospheric deposition, as is confirmed in the following section. In comparison with those values obtained for the dry season, CIC and \% SB values during rainy season decreased progressively. Seven sites presented a sensitivity class 1 (highly

Table 6. Sensitivity classes assigned to sampling sites during rainy season.

\begin{tabular}{ccccc}
\hline $\begin{array}{c}\text { Sampling } \\
\text { site }\end{array}$ & $\begin{array}{c}\mathrm{CIC} \\
(\mathrm{meq} / 100 \mathrm{~g})\end{array}$ & $\begin{array}{c}\left(\mathrm{Ca}^{2+}+\mathrm{Mg}^{2+}+\mathrm{Na}^{+}+\mathrm{K}^{+}\right) \\
\mathbf{m e q} / 100 \mathrm{~g}\end{array}$ & $\% \mathrm{SB}$ & $\begin{array}{c}\text { Sensitivity } \\
\text { class }\end{array}$ \\
\hline P1 & 0.06 & 73.20 & 73.20 & 3 \\
P2 & 6.71 & 67.48 & 10.06 & 1 \\
P3 & 11.86 & 59.64 & 5.03 & 1 \\
P4 & 16.11 & 68.94 & 4.28 & 1 \\
P5 & 14.00 & 1390.08 & 99.29 & 5 \\
P6 & 22.07 & 122.05 & 5.53 & 1 \\
P7 & 4.32 & 69.33 & 16.06 & 1 \\
P8 & 3.84 & 94.14 & 24.52 & 1 \\
P9 & 0.67 & 35.89 & 53.18 & 2 \\
P10 & 0.08 & 77.82 & 77.82 & 3 \\
P11 & 1.21 & 57.80 & 47.95 & 2 \\
P12 & 2.77 & 56.96 & 20.58 & 1 \\
P13 & 4.53 & 269.07 & 59.43 & 2 \\
\hline
\end{tabular}


sensitive), three sites had a sensitivity class 2 (moderately sensitive), two sites presented sensitivity class 3 (sensitive) and only one site did not show sensitivity (Table 6). Along this season, the following sites exhibited high sensitivities: P2, P3, P4, P6, P7, P8 y P12, with \% SB values very low because of leaching of interchangeable cations, which is characteristic at this time of year.

Besides the characteristics of the soil, the vulnerability can be exacerbated by the potential impact of regional emissions of $\mathrm{SO}_{2}$ that is long-transported from distant sources during rainy and cold fronts seasons. Both, sulfate ion and its precursor $\left(\mathrm{SO}_{2}\right)$, are considered as regional pollutants. For this reason, when $\mathrm{S}$ atmospheric deposition fluxes are measured in sites potentially impacted by regional emissions, it is difficult to find significant differences between sites, since the most of measured sulfate comes from regional sources located upwind, whose transport is more significant during these seasons in comparison with the dry season, due to prevailing meteorological phenomena that favors this transport process. Finally, site labeled as "P5" was not sensitive with a sensitivity class of 5 , and corresponds to mangrove soils. It suggests that mangrove vegetation could play an important role in the attenuation of ecological effects of S deposition.

\subsubsection{Cold Fronts Season}

CIC values during cold front season were between 9.08 and $25.45 \mathrm{meq} / 100 \mathrm{~g}$ (Table 7), with the highest values for sampling site labeled as "P13", that corresponds to soils type Solonchak, characterized by salts accumulation.

On the other hand, sampling site "P1" presented the lowest values of CIC (9.08 meq/100 g), this sampling site has a soil type Arenosol, (sandy and depth),

Table 7. Sensitivity classes assigned to sampling sites during Cold Fronts season.

\begin{tabular}{ccccc}
\hline $\begin{array}{c}\text { Sampling } \\
\text { site }\end{array}$ & $\begin{array}{c}\mathrm{CIC} \\
(\mathrm{meq} / \mathbf{1 0 0} \mathbf{g})\end{array}$ & $\begin{array}{c}\left(\mathrm{Ca}^{2+}+\mathrm{Mg}^{2+}+\mathrm{Na}^{+}+\mathrm{K}^{+}\right) \\
\mathrm{meq} / \mathbf{1 0 0} \mathrm{g}\end{array}$ & \% SB & $\begin{array}{c}\text { Sensitivity } \\
\text { class }\end{array}$ \\
\hline P1 & 9.08 & 299.96 & 33.03 & 1 \\
P2 & 12.05 & 69.48 & 5.76 & 1 \\
P3 & 21.96 & 229.39 & 10.45 & 1 \\
P4 & 9.86 & 151.18 & 15.34 & 1 \\
P5 & 10.49 & 437.48 & 41.70 & 3 \\
P6 & 16.72 & 120.55 & 7.21 & 1 \\
P7 & 9.85 & 149.90 & 15.21 & 1 \\
P8 & 9.52 & 26.42 & 2.77 & 1 \\
P9 & 10.38 & 196.98 & 18.96 & 1 \\
P10 & 11.56 & 75.52 & 6.53 & 1 \\
P11 & 12.34 & 53.02 & 4.29 & 1 \\
P12 & 15.92 & 51.67 & 3.25 & 1 \\
P13 & 25.45 & 171.75 & 6.75 & 2 \\
\hline
\end{tabular}


where leaching can be high during this season as a result of frequent and intense rains. In general, soils in sampling sites studied during this season showed CIC values from medium to low. Four sampling sites showed CIC values $<10$ meq/100 g, suggesting that they have soils very poor, whereas, seven sampling sites had CIC values between 10 and $20 \mathrm{meq} / 100 \mathrm{~g}$, pointing that, these sampling sites had soils that require an important organic matter contribution. Only two sampling sites presented values of CIC between 20 and $35 \mathrm{meq} / 100 \mathrm{~g}$, corresponding to medium soils.

\% SB values during cold fronts season were between 2.77 (site P2) and 41.70\% (site P5) (Table 7). However, it is necessary to consider that soils in sampling site "P5" are Solonchak type, characterized by a deficient drainage. All sampling sites, presented values below of 50\%, suggesting nutritional deficiencies in soils which can lead to a high vulnerability to $S$ Atmospheric Deposition during this season. In comparison with dry and rainy season, it can be observed that both, CIC and \% SB decreased drastically. Of thirteen sampling sites studied, 11 sites presented a sensitivity class of "1" that corresponds to highly sensitive; one sampling site showed class "2" (moderately sensitive), and only one site had a sensitivity class of " 3 " (sensitive).

Site "P5" presented a lower sensitivity during all seasons compared with other sites. It is necessary to emphasize that this site corresponds to a soil with mangrove vegetation. \% SB value in this site was the highest during rainy and cold fronts seasons, suggesting that this site had saturated soils in bases, being less vulnerable. In spite of intense and frequent rains occur during humid seasons (causing nutrient leaching); results suggest that the contribution of organic coverage from mangrove soils, causes that soils be fertile as a result of supply of nutrients (exchangeable cations) which tend to compensate for the loss due to leaching, making them less sensitive. This highlights the importance of mangrove conservation in the studied zone.

\subsubsection{Statistical Analysis}

1) Friedman Test for Exchangeable Cations by Season

A Friedman Test was applied to exchangeable cations by season to identify significant differences $(p \leq 0.050)$ during three climatic seasons. Significant differences were not found for rainy and cold fronts seasons, whereas for dry season, a significant difference with respect to others season was found. It is expected, since during the dry season, there are not processes that promote the cation leaching in comparison with humid seasons (rainy and cold fronts seasons).

2) Friedman Test for CIC by Season

According to Friedman test, there were significant differences $(p \leq 0.050)$ between humid seasons (rainy and cold fronts seasons) and dry season. CIC values were higher during the dry season, decreasing progressively as humid seasons progressed. CIC is a potential indicator of soils to retain and exchange nutrients. Therefore, during the dry season, soils in the study area showed a higher capacity to retain cations (since soils are not flooded, trace elements are concentrated); 
whereas during humid seasons, intense and frequent rains wash and leach surface soil layers, removing elements and resulting in a lower capacity to retain cations.

3) Friedman Test for \% SB by Season

As a result of Friedman test, it was found that there were significant differences $(p \leq 0.050)$ between dry and rainy season with respect to cold fronts season. Dry and rainy seasons did not show significant differences since these seasons presented \% SB values relatively lower that those presented during cold fronts season.

\subsection{Sulfur Deposition Fluxes}

$\mathrm{S}$ Deposition fluxes ranged from 0.29 to $14.06 \mathrm{~kg} \cdot \mathrm{ha}^{-1} \cdot \mathrm{yr}^{-1}$, with a mean value $8.57 \mathrm{~kg} \cdot \mathrm{ha}^{-1} \cdot \mathrm{yr}^{-1}$. A seasonal pattern was identified, with the highest values during the cold fronts seasons, and values significantly lower for dry season. According to Friedman test, $\mathrm{S}$ deposition fluxes showed significant differences ( $p \leq$ 0.050) between rainy and cold fronts seasons with respect the dry season.

On the other hand, S Deposition fluxes did not vary significantly between sampling sites. According to Friedman Test, only three sites showed significant differences (sites P2, P8 and P10). Site P2 presented the highest value (9.64 $\mathrm{kg} \cdot \mathrm{ha}^{-1} \cdot \mathrm{yr}^{-1}$ ), this site is located at the Eastern edge of Atasta peninsula, so that, it is more exposed and influenced by pollutants transported from offshore platforms in Campeche Sound; whereas sites P8 and P10 presented the lowest values for $\mathrm{S}$ deposition fluxes. In the remaining sampling sites, $\mathrm{S}$ deposition fluxes were homogeneous, demonstrating the regional character of this pollutant.

\subsection{Influence of Seasonality on Sensitivity of the Studied Area}

Sensitivity showed a seasonal variability: Cold Fronts $>$ Rainy $>$ Dry. This trend could intensify the adverse ecological effects, since this fact, is totally in agreement with S Deposition patterns. During the dry season, regional contribution is minimal, limited to background levels with a local origin. As rainy season progress, this site is influenced by tropical waves, low-pressure systems, storms and hurricanes that favor the transport of air-masses in the meso-scale, transporting $\mathrm{SO}_{2}$ from regional sources located upwind to E-SE from studied zone, increasing in a significant way $\mathrm{S}$ deposition in this region. Consequently, during Cold Front season, background levels are drastically increased, since, they are phenomena that transport air-masses from North of Mexico and United States of America, carrying pollutants released upwind from sources located at $\mathrm{N}$ and NE from studied zone. Kahl et al. [21] studied transport characteristics in the Gulf of Mexico, using resources as re-analysis data at global scale, trajectory analysis and local wind measurements. They reported emissions of sulfate precursors in sources located both, northeast and southeast from Gulf of Mexico (including offshore platforms in Campeche Sound and industrial facilities in the North of Mexico and the South of United States), in spite of these industrial fa- 
cilities are located between 500 and $1000 \mathrm{~km}$ upwind from the studied zone, respectively. Kahl et al. [21] reported that there are two main meteorological patterns controlling the transport in the Gulf of Mexico during the humid season. The first, the east flow that dominates the transport during the rainy season, when air-masses cross over Caribbean Sea, Yucatan Peninsula and the South of Gulf of Mexico. The second regime, a North-Northeast flow associated to North American cyclone that influences during the winter or cold fronts season, when air-masses are transported from Central and South of the United States crossing Texas, the North of Gulf of Mexico and the Northern part of Mexico. Among the sources that contribute to this increase, are offshore platforms in Campeche Sound during the rainy season, and industrial facilities in Tampico, Monterrey, Tuxpan, Matamoros, Poza Rica, Texas and Brownsville during the cold fronts season. According to wind speeds prevailing along these seasons (Rainy and Cold fronts), transport times estimated range from 1 to 5 days, therefore, given the location of the study area, it can be concluded that transport of regional emissions located upwind at E-SE and N-NE contribute significantly to atmospheric Sulphur deposition in the study area, being higher during cold fronts season. This fact is agreeing with sensitivity classes obtained, since during rainy season, seven of a total of thirteen sampling sites presented a sensitivity class of "1" (highly sensitive), whereas that, during the cold fronts season, eleven of a total of thirteen sampling sites showed this sensitivity class.

\subsection{Critical Loads and Exceedances}

From obtained sensitivity classes for each sampling site during three climatic seasons, critical loads and their exceedances were calculated by using the empirical method proposed by Kuylenstierna et al. [2].

\subsubsection{Dry Season}

Only six sampling sites of a total of thirteen presented exceedances, and they were relatively low, excepting site "P10" that showed an exceedance major than $50 \%$ and $\%$ SB of $18 \%$.

Exceedance values obtained were $15.63 \%, 11.44 \%, 6.80 \%, 1.66 \%$ y $53.40 \%$ for sampling sites P4, P5, P6, P7, P8 y P10, respectively (Table 8). These results suggest that taking in account physical and chemical properties of soils in the study area during the dry season, there is not a potential risk of adverse effects on ecosystems during this season as a result of $\mathrm{S}$ atmospheric deposition, since the capacity of cationic exchange is high. Likewise, the vulnerability is low because the study zone during this season is only influenced by local processes. It is clear that site labeled as "P10" during this season constitutes an isolated case, whose vulnerability depends on degree of disturbance inherent to soil characteristics in this sampling point.

\subsubsection{Rainy Season}

Only five of a total of thirteen sampling sites did not show exceedances. Two 
Table 8. Critical loads and exceedances for dry season.

\begin{tabular}{ccccc}
\hline $\begin{array}{c}\text { Sampling } \\
\text { site }\end{array}$ & $\begin{array}{c}\text { Sensitivity } \\
\text { class }\end{array}$ & $\begin{array}{c}\text { Critical load } \\
\left(\mathrm{kg} \cdot \mathrm{ha}^{-1} \cdot \mathrm{yr}^{-1}\right)\end{array}$ & $\begin{array}{c}\text { S deposition flux } \\
\left(\mathrm{kg} \cdot \mathrm{ha}^{-1} \cdot \mathrm{yr}^{-1}\right)\end{array}$ & $\begin{array}{c}\text { Exceedance } \\
(\%)\end{array}$ \\
\hline P1 & 3 & $8.01-16.03$ & 10.40 & 0 \\
P2 & 3 & $8.01-16.03$ & 10.85 & 0 \\
P3 & 3 & $8.01-16.03$ & 9.95 & 0 \\
P4 & 2 & $4.007-8.01$ & 9.50 & 15.63 \\
P5 & 2 & $4.007-8.01$ & 9.05 & 11.44 \\
P6 & 2 & $4.007-8.01$ & 8.60 & 6.80 \\
P7 & 2 & $4.0075-8.015$ & 8.15 & 1.66 \\
P8 & 2 & $4.007-8.01$ & 8.15 & 1.66 \\
P9 & 3 & $8.01-16.03$ & 7.70 & 0 \\
P10 & 1 & $0-4.007$ & 8.60 & 53.40 \\
P11 & 4 & $16.03-32.06$ & 9.05 & 0 \\
P12 & 5 & $>32.06(\mathrm{There} \mathrm{is} \mathrm{not}$ & 9.50 & 0 \\
P13 & 3 & $8.01-16.03$ & 9.95 & 0 \\
\hline & & & &
\end{tabular}

sites presented exceedances minor than 50\%; whereas six sampling sites presented exceedances major than $50 \%$.

Comparing with dry season, exceedance percentages obtained during rainy season were higher. Exceedance percentage values obtained were 51.13\%, $53.40 \%, 55.47 \%, 59.11 \%, 60.71 \%$ and $55.47 \%$ for sampling sites P2, P3, P4, P6, $\mathrm{P7}$, and P8, respectively (Table 9). Sampling site labeled as "P5" was less sensitive, and corresponds to a soil with mangrove vegetation, highlighting the important role that mangrove ecosystem plays in the attenuation process of effects attributed to atmospheric Deposition.

\subsubsection{Cold Fronts Season}

Eleven of a total of thirteen sampling sites showed exceedance percentages major than $50 \%$. Site labeled as "P13" showed an exceedance of $22.93 \%$, and only one site (site P5) did not show exceedance (Table 10). In comparison with dry and rainy seasons, exceedance percentages obtained along this season increased progressively. Likewise, sampling site labeled as "P5" was the less sensitive, which corresponds to mangrove ecosystem.

\subsection{Mapping Sensitivity Class and S Deposition Fluxes}

Once sensitivity classes were obtained, software SURFER v.10.0 was applied to obtain maps showing both, sensitivity classes and S deposition fluxes, to identify spatial trends, temporal patterns and critical zones with a high vulnerability.

\subsubsection{Dry Season}

In Figure 2, it is possible to observe that sensitivity did not show any spatial 
Table 9. Critical loads and exceedances for rainy season.

\begin{tabular}{ccccc}
\hline $\begin{array}{c}\text { Sampling } \\
\text { site }\end{array}$ & $\begin{array}{c}\text { Sensitivity } \\
\text { class }\end{array}$ & $\begin{array}{c}\text { Critical load } \\
\left(\mathrm{kg} \cdot \mathrm{ha}^{-1} \cdot \mathrm{yr}^{-1}\right)\end{array}$ & $\begin{array}{c}\text { S deposition flux } \\
\left(\mathrm{kg} \cdot \mathrm{ha}^{-1} \cdot \mathrm{yr}^{-1}\right)\end{array}$ & $\begin{array}{c}\text { Exceedance } \\
(\%)\end{array}$ \\
\hline P1 & 3 & $8.01-16.03$ & 7.80 & 0 \\
P2 & 1 & $0-4.007$ & 8.20 & 51.13 \\
P3 & 1 & $0-4.007$ & 8.60 & 53.40 \\
P4 & 1 & $0-4.007$ & 9.00 & 55.47 \\
P5 & 5 & $>32.06$ & 9.40 & 0 \\
P6 & 1 & $0-4.007$ & 9.80 & 59.11 \\
P7 & 1 & $0-4.007$ & 10.20 & 60.71 \\
P8 & 1 & $0-4.007$ & 9.00 & 55.47 \\
P9 & 2 & $4.007-8.01$ & 8.60 & 6.80 \\
P10 & 3 & $8.01-16.03$ & 8.20 & 0 \\
P11 & 2 & $4.007-8.01$ & 7.80 & 0 \\
P12 & 1 & $0-4.007$ & 7.40 & 45.84 \\
P13 & 2 & $4.007-8.01$ & 7.00 & 0 \\
\hline
\end{tabular}

Table 10. Critical loads and exceedances for cold fronts season.

\begin{tabular}{ccccc}
\hline $\begin{array}{c}\text { Sampling } \\
\text { site }\end{array}$ & $\begin{array}{c}\text { Sensitivity } \\
\text { class }\end{array}$ & $\begin{array}{c}\text { Critical load } \\
\left(\mathrm{kg} \cdot \mathrm{ha}^{-1} \cdot \mathrm{yr}^{-1}\right)\end{array}$ & $\begin{array}{c}\text { S deposition flux } \\
\left(\mathrm{kg} \cdot \mathrm{ha}^{-1} \cdot \mathrm{yr}^{-1}\right)\end{array}$ & $\begin{array}{c}\text { Exceedance } \\
(\%)\end{array}$ \\
\hline P1 & 1 & $0-4.007$ & 8.80 & 54.46 \\
P2 & 1 & $0-4.007$ & 9.20 & 56.44 \\
P3 & 1 & $0-4.007$ & 9.60 & 58.25 \\
P4 & 1 & $0-4.0075$ & 10.00 & 59.93 \\
P5 & 3 & $8.01-16.03$ & 10.40 & 0 \\
P6 & 1 & $0-4.007$ & 11.20 & 64.22 \\
P7 & 1 & $0-4.007$ & 10.80 & 62.89 \\
P8 & 1 & $0-4.007$ & 10.00 & 59.93 \\
P9 & 1 & $0-4.007$ & 9.60 & 58.26 \\
P10 & 1 & $0-4.007$ & 9.20 & 56.44 \\
P11 & 1 & $0-4.0075$ & 8.80 & 54.46 \\
P12 & 1 & $0-4.0075$ & 10.00 & 59.93 \\
P13 & 2 & $4.0075-8.015$ & 10.40 & 22.93 \\
\hline
\end{tabular}

trend, and it is related with inherent soil characteristics that prevail in each sampling site. Site "P10" which presents a vulnerability class of "1" (highly sensitive) corresponds to sour gas recompression plant, suggesting that, the observed vulnerability is more influenced by local sources and disturbance degree in the studied soils. In Figure 3, it is possible to identify the eastern edge of Atasta Peninsula and the surroundings of sour gas recompression plant as critical zones, 


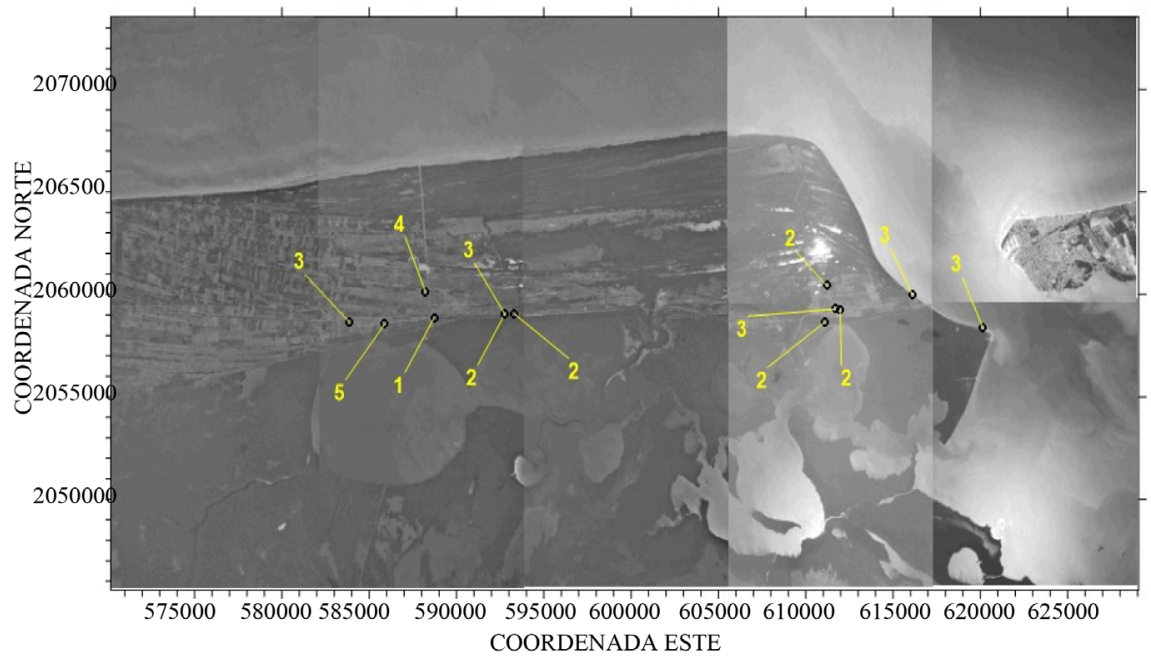

Figure 2. Sensitivity Class Map for the studied area during the dry season.

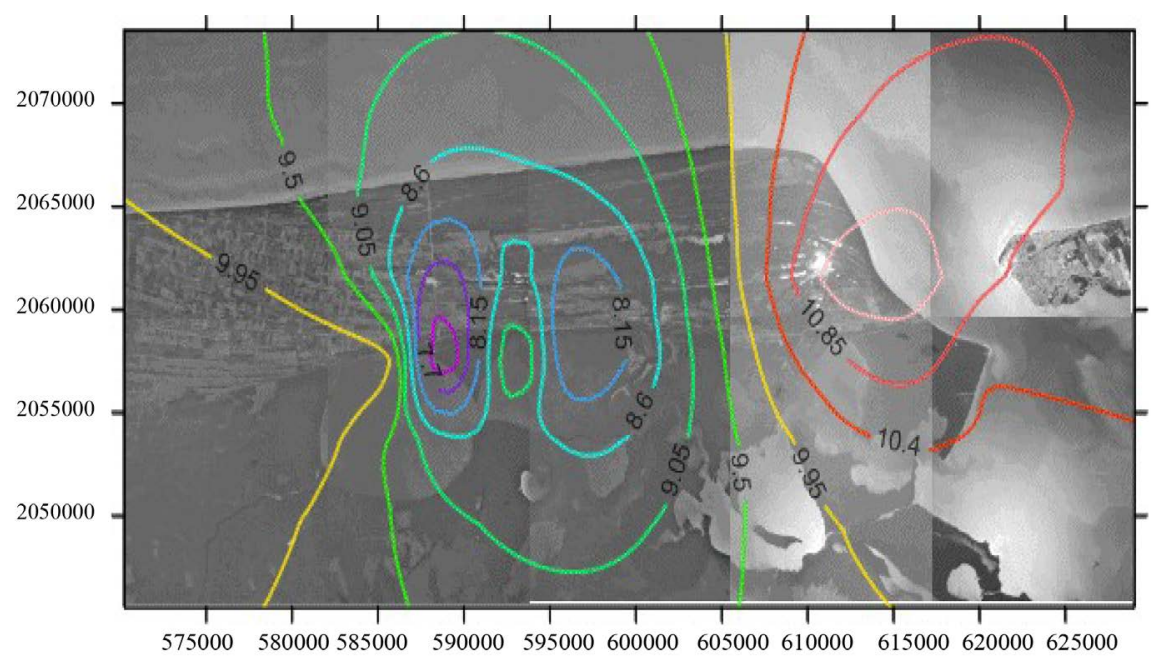

Figure 3. S Deposition Fluxes Map for the studied area during the dry season.

presenting the highest $\mathrm{S}$ deposition fluxes.

\subsubsection{Rainy Season}

From Figure 4, it can be observed that sensitivity showed a slight spatial variation, with higher sensitivity classes in the Eastern edge of Atasta Peninsula, since this region is more exposed to air-masses coming from East as a result of meteorological conditions prevailing along this climatic season. In addition, a sensitivity class of "1" was found in the surroundings of sour-gas recompression plant. From Figure 5, it can be observed that higher S deposition fluxes were found in the surroundings of sour gas recompression plant (site P10), just where sensitivity classes were higher.

\subsubsection{Cold Fronts Season}

Sensitivity showed a complete uniformity, with a sensitivity class of "1" (highly sensitive) in most sampling sites (Figure 6), suggesting a regional influence as 


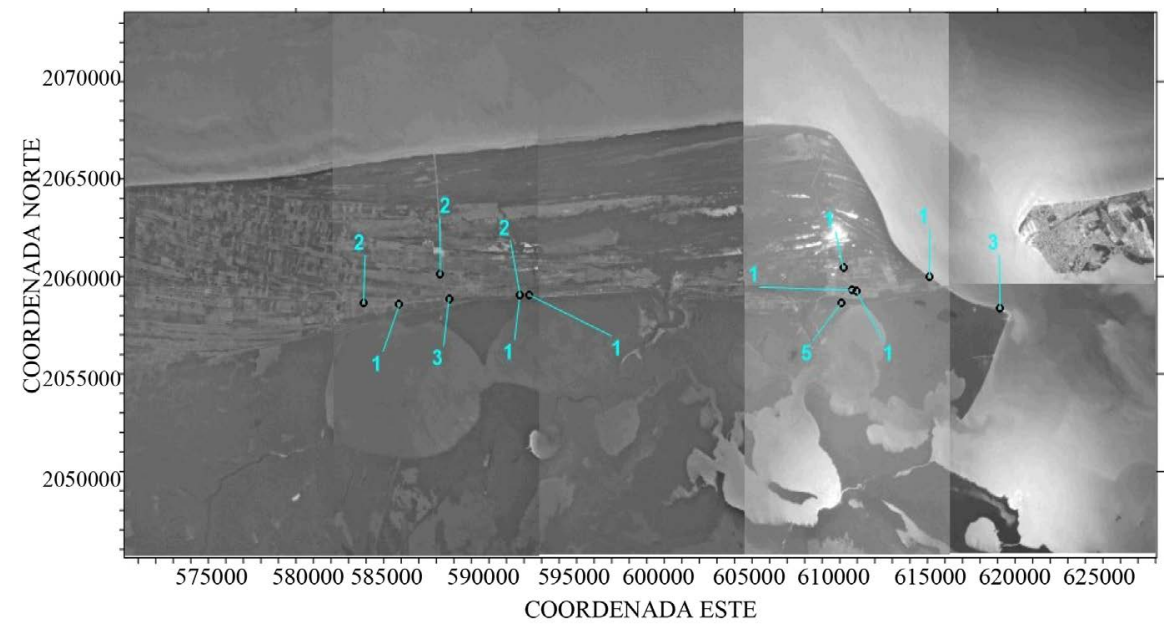

Figure 4. Sensitivity Class Map for the studied area during the rainy season.

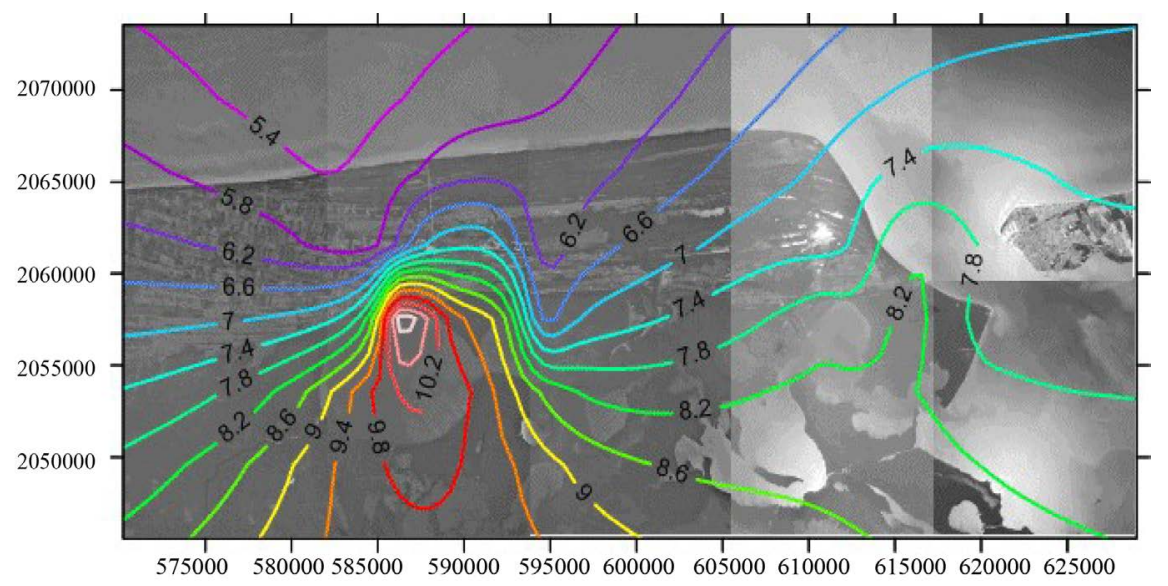

Figure 5. S Deposition Fluxes Map for the studied area during the rainy season.

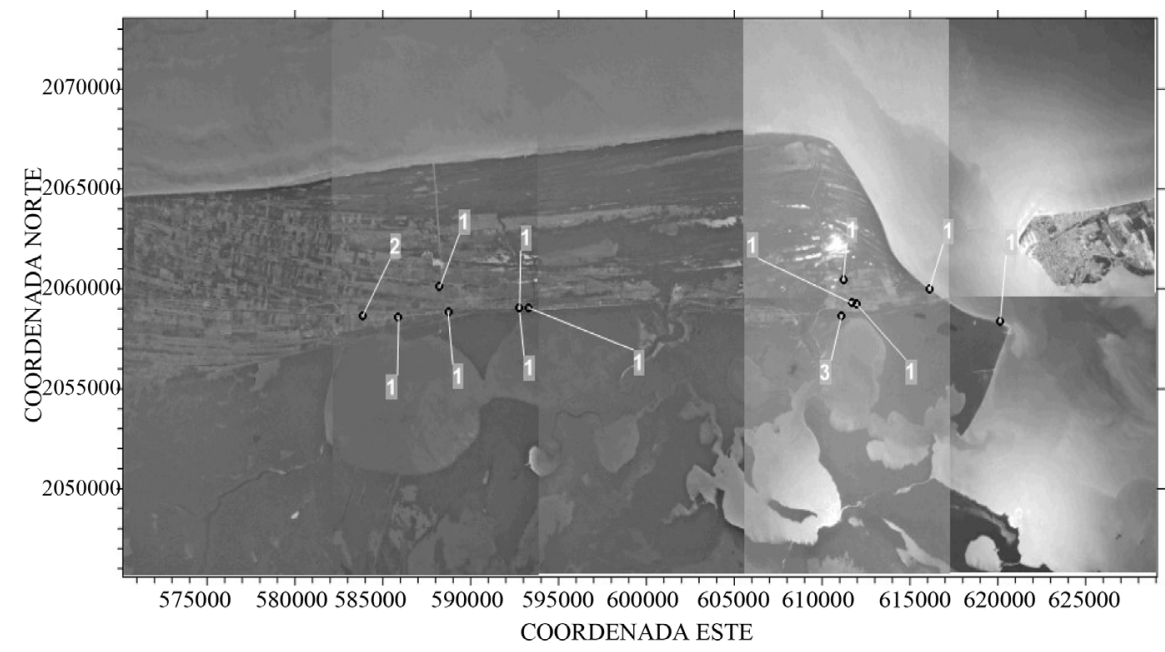

Figure 6. Sensitivity Class Map for the studied area during the cold fronts season.

result of long-range transport from sources located upwind at $\mathrm{N}$ and NE. As can be observed from Figure 7, during cold fronts season, $\mathrm{S}$ atmospheric Deposition 


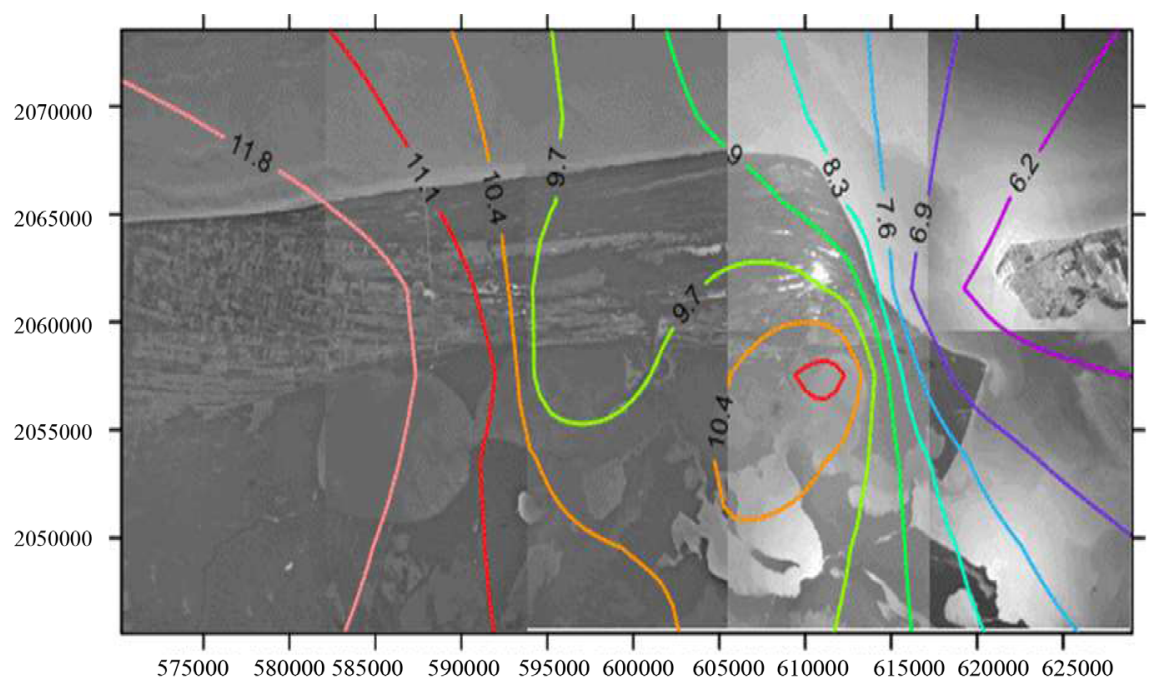

Figure 7. S Deposition Fluxes Map for the studied area during the cold fronts season.

fluxes are very high in comparison with dry and rainy seasons, being higher in the northern part of Atasta Peninsula and in the surroundings of sour-gas recompression plant, as a result of prevailing meteorology along this season.

In addition, $S$ deposition fluxes were higher in those sampling sites which presented a sensitivity class of "1" (highly sensitive). It suggests that, there may be two factors acting in synergy to exacerbate the potential effects on ecosystems of the region: soil characteristics and exposition pattern to regional pollutants during this season.

\section{Conclusion}

Results obtained in this study constituted the first approximation in the Southern of Mexico to establish critical loads level " 0 ", giving a preliminary assessment about the vulnerability based on criteria proposed by Kuylenstierna et al. [2]. It can be concluded that sensitivity of terrestrial ecosystems in Atasta-Xicalango region has a seasonal component well defined, with the following trend: Cold Fronts $>$ Rainy $>$ Dry. This same seasonal trend was obtained from S deposition fluxes maps, with the highest fluxes when the studied zone was subject to the influence of meteorological phenomena occurring at mesoscale. During the dry season, regional contribution was minimal, limited to background levels with a local origin. Both factors, soil characteristics and prevailing meteorology act in synergy to intensify the potential ecological effects associated to $S$ Atmospheric deposition. However, it was demonstrated that soils with mangrove vegetation present a minor sensitivity, highlighting the importance of conserving this kind of ecosystems in this region.

\section{References}

[1] Lovland, G., Andersen, B., Joffre, S., Pedersen, U., Hormand, M. and Reisell, A. (1992) Mapping Deposition of Sulphur, Nitrogen, and Base Cations in the Nordic Countries. Swedish Environmental Research Institute, Report B 1055. 
[2] Kuylenstierna, J., Rodhe, H., Cinderby, S. and Hicks, K. (2001) Acidification in Developing Countries: Ecosystem Sensitivity and the Critical Load Approach on a Global Scale. Journal of the Human Environment, 30, 20-28. https://doi.org/10.1579/0044-7447-30.1.20

[3] Pardo, L., Fenn, M.E., Goodale, C., Geiser, L., Driscoll, C. and Allen, E. (2011) Effects of Nitrogen Deposition and Empirical Nitrogen Critical Load for Ecoregions of the United States. Ecological Applications, 21, 3049-3082.

http://mds.marshall.edu/bio_sciences_faculty https://doi.org/10.1890/10-2341.1

[4] Cerón, R.M., Cerón, J.G., García, A., Ramírez, E., Aguilar, C., Montalvo, C., Córdova, A. and Alderete, A. (2015) Through Fall Deposition Patterns for Nitrogen and Sulphur on Ecosystems Adjacent to One Sour Gas Recompression Plant in Campeche, Mexico. Proceedings of International Conference on Recent Advances on Mechanics, Materials, Mechanical Engineering and Chemical Engineering, Barcelona, 7-9 April 2015, 195-202.

[5] Fenn, M.E., De Bauer, L.I. and Hernández-Tejeda, T. (2002) Summary of Air Pollution Impacts on Forest in the Mexico City Air Basin. In: Fenn, M.E., Bauer, L.I. and Hernández-tejeda, T., Eds., Urban Air Pollution and Forests. Resources at Risk in the Mexico City Air Basin, Ecological Studies Series, Vol. 156, Springer-Verlag, New York.

[6] UNECE (1996) Manual on Methodologies and Criteria for Mapping Critical Levels/Loads and Geographical Areas Where They Are Exceeded. UNECE Convention on Long-Range Transboundary Air Pollution. Federal Environmental Agency, Berlín, Texte 71/96.

[7] Turchenek, L.W. (2007) Properties of Sensitive Soils in the Athabasca Oil Sands Area, Alberta. Cumulative Environmental Management Association. Rural Municipality of Wood Buffalo. Report EE31131, Fort McMurray, Alberta.

[8] Nagel, H.D. and Gregor, H.D. (2001) Derivation and Mapping of Critical Loads for Nitrogen and Trends in Their Exceedance in Germany. The Scientific World Journal, 1, 936-944. https://doi.org/10.1100/tsw.2001.330

[9] Fenn, M.E., De Bauer, L.I., Quevedo-Nolasco, A. and Rodríguez-Frausto, C. (1999) Nitrogen and Sulphur Deposition and Forest Nutrient Status in the Valley of Mexico. Water, Air and Soil Pollution, 113, 155-174. https://doi.org/10.1023/A:1005033008277

[10] Turchenek, L.W., Abboud, S., Tomas, C., Fessenden, R. and Holawaychuk, A.N. (1987) Effects of Acid Deposition on Soils in Alberta. Report ADRP-B-05-87, 202, Acid Deposition Research Program, Calgary.

[11] Turchenek, L.W. and Abboud, S. (2001) Site-Specific Critical Loads of Acid Deposition on Soils in the Provost-Esther Area, Alberta. Air and Water Branch, Science and Standards Division, Alberta Environment Pub No. T/609, Alberta.

[12] Josipovic, M., Annegarn, H.J., Kneen, M.A., Pienaar, J.J. and Piketh, S.J. (2011) Atmospheric Dry and Wet Deposition of Sulphur and Nitrogen Species and Assessment of Critical Loads of Acidic Deposition Exceedance in South Africa. South African Journal of Science, 107, 1-10. https://doi.org/10.4102/sajs.v107i3/4.478

[13] Pérez-Suárez, M., Fenn, M.E., Cetina-Alcalá, V.M. and Aldrete (2008) The Effects of Canopy Cover on Throughfall and Soil Chemistry in Two Forest Sites in the Mexico City Air Basin. Atmosfera, 21, 83-100.

[14] Ponette-González, A.G., Weathers, K.C. and Curran, L.M. (2010) Tropical Land-Cover Change Alters Biogeochemical Inputs to Ecosystems in a Mexican 
Montane Landscape. Ecological Applications, 20, 1820-1837. https://doi.org/10.1890/09-1125.1

[15] Fenn, M.E. and Poth, M. (2004) Monitoring Nitrogen Deposition in Throughfall using Ion Exchange Resin Columns: A Field Test in the San Bernardino Mountains. Journal of Environmental Quality, 30, 2007-2014. https://doi.org/10.2134/jeq2004.2007

[16] NOM-021-RECNAT-2000 (2002) Secretaría del Medioambiente y Recursos Naturales. Norma oficial mexicana. Especificaciones de fertilidad, salinidad, clasificación de suelos. Estudio, muestreo y análisis. Diario Oficial de la Federación. 31 de Diciembre de 2002. [Natural Resources and Environment Secretary. Mexican Official Standard. Specifications of Fertility, Salinity, and Soil Classification. Study, Sampling and Analysis. Official Journal of the Federation. December 31, 2002.]

[17] NMX-AA-074-SCFI-1981 (1992) Secretaría de Economía y Fomento Industrial. Norma oficial mexicana. Análisis de aguas. Determinación del ión sulfato en aguas naturales, potables, residuales y residuales tratadas. Diario Oficial de la federación. 6 de Noviembre de 1992. [Economy and Industrial Development Secretary. Mexican Official Standard. Water Analysis. Sulfate Determination in Natural, Drink Water, Wastewater and Treated Wastewater. Official Journal of the Federation. November 6, 1992.]

[18] Nilsson, J. and Grennfelt, P. (1988) Critical Loads for Sulphur and Nitrogen. Report from Skokloster Workshop. Skokloster. https://doi.org/10.1007/978-94-009-4003-1_11

[19] Duan, L., Hao, J., Jenkins, A., Collins, R., Evans, C. and Xie, S. (2000) Mapping Critical Loads of Acid Deposition for Soils in China. Tsinghua Science and Technology, 5, 270-278.

[20] Garrido, M.S. (2010) Interpretación del análisis de suelos. Hojas informativas. Ministerio de Agricultura, Pesca y Alimentación. [Interpretation of Soil Analysis. Informative Sheets. Ministry of Agriculture, Fishing and Food.] Rivadeneyra S.A., Madrid.

[21] Kahl, J.D.W., Bravo, H., Sosa, R., Sánchez, P. and Soto, R. (1997) Characterization of Atmospheric Transport to El Tajin Archaeological Zone in Veracruz, Mexico. Atmosfera, 20, 359-371.

\section{Submit or recommend next manuscript to SCIRP and we will provide best} service for you:

Accepting pre-submission inquiries through Email, Facebook, LinkedIn, Twitter, etc. A wide selection of journals (inclusive of 9 subjects, more than 200 journals)

Providing 24-hour high-quality service

User-friendly online submission system

Fair and swift peer-review system

Efficient typesetting and proofreading procedure

Display of the result of downloads and visits, as well as the number of cited articles

Maximum dissemination of your research work

Submit your manuscript at: http://papersubmission.scirp.org/

Or contact jep@scirp.org 